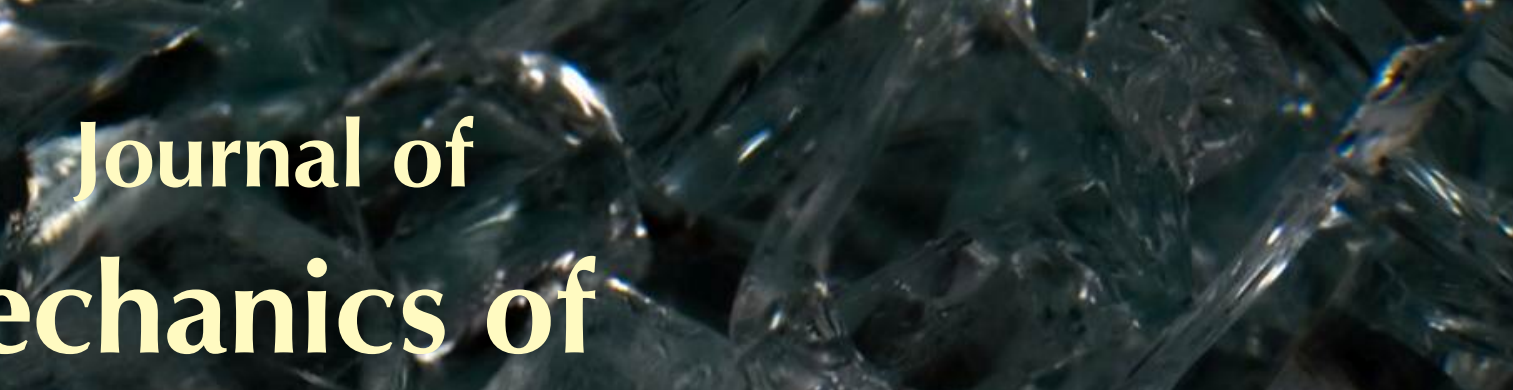

Materials and Structures

Mechanics of

0. 


\title{
MULTIOBJECTIVE OPTIMIZATION OF LAMINATED COMPOSITE PLATE WITH ELLIPTICAL CUT-OUT USING ANN BASED NSGA-II
}

\author{
P. Emmanuel Nicholas, M. C. Lenin Babu And A. Sathya Sofia
}

\begin{abstract}
Laminated composites are highly in demand for the applications where high strength and stiffness are required at less weight. They generally fail due to buckling, as they are modeled as thin plates and are loaded compressively. Therefore, the design parameters of the laminated composite plates are to be optimized for the multiple-conflicting objectives buckling strength and weight. However, the composite plates, which are used in real world applications, are to be made with cut-outs and finite element analysis is required to analyze them. As it makes the optimization process more complex, a methodology is proposed in this paper to carry out a multiobjective optimization for the rectangular composite plate made with a central elliptical cut-out. The nondominated solutions are obtained using nondominated sorting genetic algorithm (NSGA-II) in which the multilayer feed-forward neural network is used to replace the time consuming finite element analysis. The numerical results show that the proposed method finds the nondominated solutions efficiently and reduces the computational cost prominently.
\end{abstract}

\section{Introduction}

Fiber reinforced laminated composite structures have high specific strength and stiffness and so, they are widely used in aerospace industries, automobile industries and wind turbine blades. In those applications, they are generally modeled as thin plates and shells and are compressively loaded. Hence, they generally fail due to buckling and it is mandatory to optimize the design variables of the composite plates for the multiple objectives such as maximum buckling strength and minimum weight. Aymerich and Serra [2008] optimized conventional ply angles $\left(0^{\circ} / \pm 45^{\circ} / 90^{\circ}\right)$ to increase the buckling strength of the composite plate. Almeida and Awruch [2009] carried out a multiobjective optimization to minimize the weight and deflection of the composite plate. The conventional ply angles were used as design variables and finite element method was used to evaluate the buckling strength of the structure. Omkar et al. [2009; 2011] have optimized the composite plate for the multiple objectives weight and the total cost. These multiobjective optimization problems were solved in the similar fashion of the single objective optimization problem by assigning the suitable weights to the objective functions. However, the exact values of the weights cannot be obtained, as the importance of each objective function cannot be clearly quantified in the multiobjective optimization problems. Further, the ply angles having the same orientation are grouped in the optimum stacking sequences, as conventional ply angles are generally optimized to improve the structural behavior of the composites. Kim et al. [2005] and Kim [2007] stated that the thickness of the ply having a particular orientation is increased when the plies having the same orientation are stacked together. They also mentioned that the interlaminar normal and shear stresses are developed due to the grouping of plies having the same orientation. Campbell [2010] and Emmanuel Nicholas et

Keywords: stacking sequence optimization, artificial neural network, NSGA-II, finite element analysis. 
al. [2014] recommend for maintaining the dispersed stacking sequences so as to avoid grouping of plies having the same orientation.

In real world applications, it is indispensable to design the composite plates with cut-outs (holes) in order to provide fasteners to assemble them as a complex structure. In aircraft industries, the cut-outs are necessary to function as doors, windows and access ports. Al Qablan et al. [2009] stated that the cut-outs are necessary for accessibility reasons and to reduce the weight of the composite structure. The finite element analysis was used to find the buckling strength of the composite plate with cut-outs. Liu et al. [2006] indicated that the design of interior cut-outs in laminated composite structures is of great importance in the aerospace, automobile and structural engineering. Lopes et al. [2010] mentioned that the cut-outs on composite structures are required to accommodate windows, doors, and bolted joints. Aydin Komur et al. [2010] referred that the cut-outs are generally used in composites as design necessities. They analyzed the buckling strength of a woven-glass-polyester laminated composite plate with circular/elliptical cutout. The finite element method was used to study the effect of the cutout shape on the buckling strength. Erklig and Yeter [2012] used finite element analysis to study the effects of various cut-out shapes on the lateral buckling behavior of composite beams. Iyengar and Vyas [2011] carried out an optimization process to maximize the buckling load of the laminated composite plate with and without cut-out. However, the design space was restricted by using very few ply angles $\left( \pm 60^{\circ}, \pm 45^{\circ}, \pm 30^{\circ}, 0^{\circ} / 90^{\circ}\right)$ as the design variables. Liu et al. [2006] and Lopes et al. [2010] performed the shape optimization of multiple interior cutouts by varying $[\theta /-\theta]_{2 s}$ stacking sequences. Rocha et al. [2014] considered the laminated composite curved panel with a central circular cutout that is generally used in aerospace applications. He optimized the structure consists of 8 plies by varying the conventional ply angles and ply thickness.

The artificial neural network is generally used as a prediction tool in the applications, where the opportunities are not available or not possible to find the actual targets. Recently, ANN has been successfully used to approximate the mechanical behaviors of the laminated composites. Zheng et al. [2009] successfully used the wavelet neural network to estimate the delamination locality. Bilgehan [2011] used artificial neural network to analyze the buckling strength of slender prismatic columns. Chakraborty [2005] used natural frequencies as inputs to the artificial neural network and predicted the existence of embedded delaminations based on their size, shape and location in FRP composites. The natural frequencies of laminated composite for different blends of size, shape and location of an embedded delamination were obtained using finite element method and these samples have been used to train a back propagation neural network (BPNN) to predict the delaminations in the composite structure. Karnik et al. [2008] carried out delamination analysis in high speed drilling with the application of artificial neural network model. The spindle speed, feed rate and point angle were used as the input parameters to the network structure.

Tsao and Hocheng [2008] used radial basis function network (RBFN) and predicted the thrust force and surface roughness in composite materials during the drilling process. Al-Assaf and El Kadi [2001] applied ANN to predict the mechanical properties of fiber reinforced polymeric composites. They examined the possibility of using neural network to predict the failure due to fatigue. The ply angle, stress ratio and maximum stress were given as the inputs to the network and the number of cycles to failure has been found as the output. Al-Haik et al. [2006] studied the visco-plastic behavior of composites using a neural networks formulation. Mishra et al. [2010] used artificial neural network to predict the residual tensile strength of unidirectional glass fiber reinforced plastic laminates with drilled hole. The drill point geometry, feed rate and the spindle speed have been used as the input variables to the network. 
The number of neurons in the input and output layers were equal to the number of input and output parameters. The number of neurons in the hidden layer was optimally found based on trial and error method. Reddy et al. [2013] used artificial neural networks to predict the deflection and stresses of carbon fiber reinforced plastic (CFRP) laminated composite square plate subjected to uniformly distributed load. Cardozo et al. [2011] used ANN based optimization method to optimize the stacking sequence of laminated composite. However, the work is limited by using only the conventional ply angles.

It is observed from the literature review that many research works have been done on stacking sequence optimization of rectangular laminated composite plate to increase the buckling strength and reduce the weight of the structure. The in-plane and buckling strengths of the rectangular composite plate were computed analytically during the optimization process. However, the literature review also reveals that the composite plate, which is to be used in real world applications, has to be made with cut-out. Further, it is exposed that the plate made with cut-out has to be analyzed using FEM and this increases the computational cost. Though many researchers used FEM and ANN and studied the influences of cutout size, shape and its location on buckling strength and other mechanical behaviors of the composite plate, the design factors of the composite plate made with cut-out have not been optimized adequately. In addition, the conventional ply angles have been generally used as the design variables and also the complex multiobjective optimization problems have been solved like the single objective optimization problems. Hence, the ANN based methodology is proposed in this paper to obtain the Pareto-optimal designs for the laminated composite plate made with cut-out, whereas the design space is critically increased with the choice of reduced ply angle intervals.

\section{Problem definition and solution methodology}

2.1. Problem definition. The rectangular composite plate with central elliptical cut-out shown in Figure 1 is considered in this research work whereas the cut-out is oriented at an angle $60^{\circ}$ from the major coordinate axis. The simply supported boundary conditions and biaxial compressive loads are applied on all the four sides of the plate. The ply angle $(\theta)$, number of plies (n) and stacking sequence are chosen as design variables and the in-plane strengths obtained using Tsai-Wu criterion is set as design constraint. The design space is critically increased using the concept of ply angles having the reduced intervals so as to improve the degree of the objective functions and to reduce the number of grouping of plies having the same orientation. The objective functions, design variables and constraints are defined in Equation (1).

Maximize the buckling strength $\lambda_{b}=f\left(\left[\theta_{1} / \theta_{2} / \theta_{3} \ldots / \theta_{n}\right]\right)$

and minimize the weight (total thickness) $T=\sum_{i=1}^{k} t_{i}$

subject to $\theta_{i}=-90^{\circ}$ to $90^{\circ}$ with an increment " $\Delta$ "

$t_{i}=0$ or $0.125 \mathrm{~mm}$

$f_{1} \sigma_{11} i+f_{2} \sigma_{22}+f_{6} \sigma_{12}+f_{11} \sigma_{11}^{2}+f_{22} \sigma_{22}^{2}++f_{66} \sigma_{12}^{2}+2 f_{12} \sigma_{11} \sigma_{22} \leq 1$

$G \leq 4$

where $n=$ number of plies in the plate

$t_{i}=$ thickness of each ply " $i$ "

$\Delta=$ any value of $45^{\circ}, 15^{\circ}, 5^{\circ}$ and $1^{\circ}$

$i=1,2,3, \ldots, n / 2$ (i.e., stacking sequence is symmetric)

and $G=$ number of continuous plies having the same orientation. 
2.2. Solution methodology. The artificial neural network is considered in the optimization procedure to predict the buckling strength of the laminated composite plate made with cut-out. The proposed optimization method comprises of three modules. In the first module, the stacking sequences of the laminated plate made with cut-out are randomly generated using MATLAB code and buckling strength

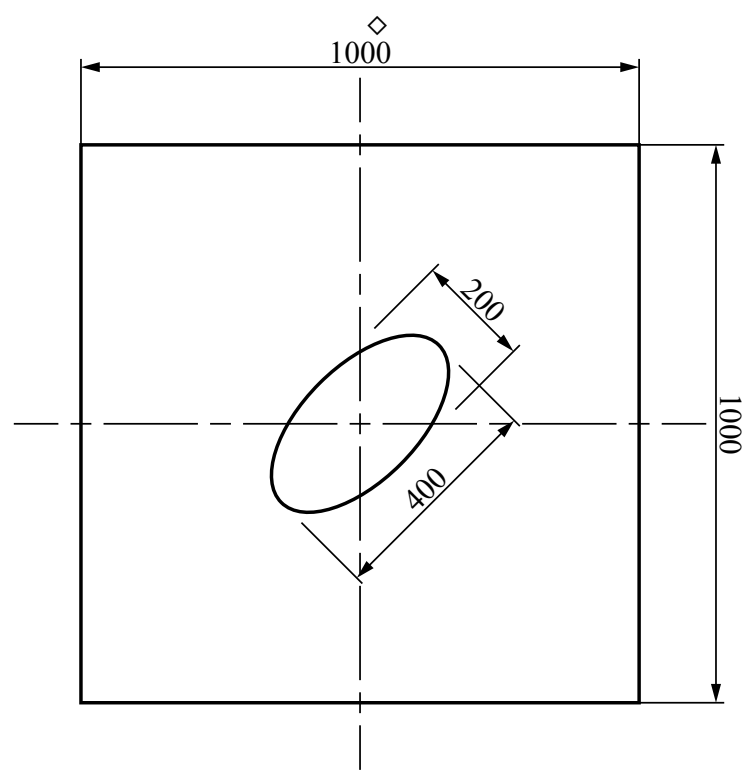

Figure 1. Geometry of the structure.

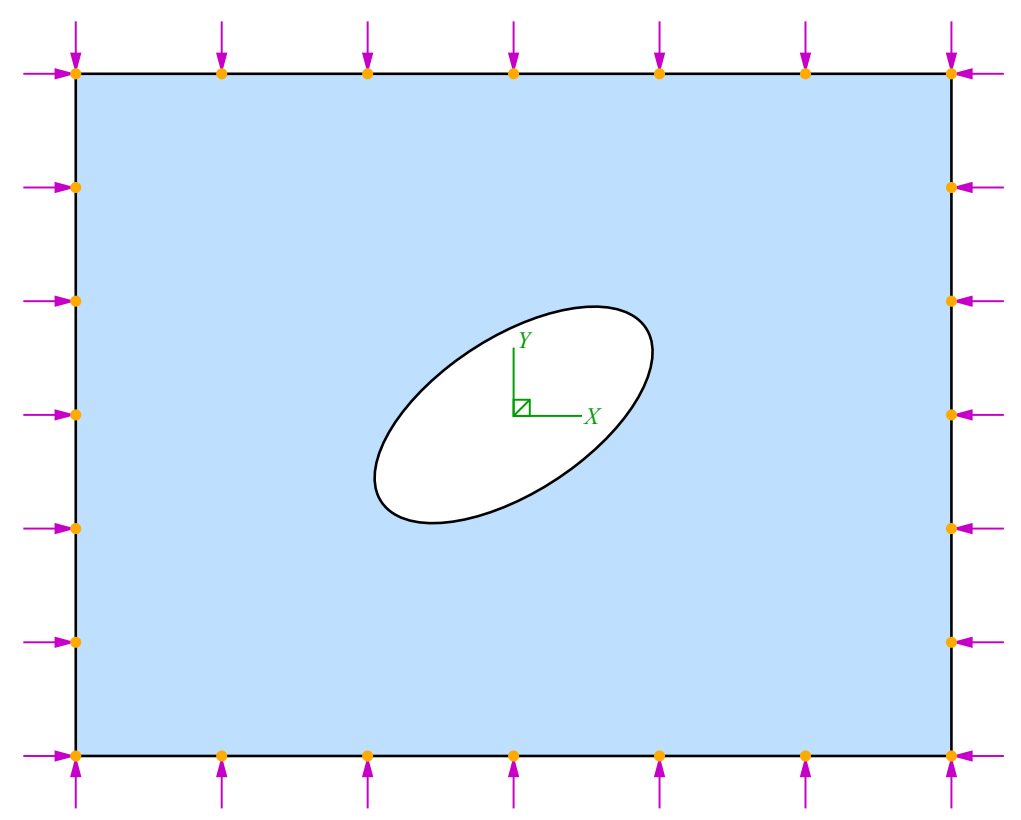

Figure 2. Loading and boundary conditions. 


\begin{tabular}{|c|c|}
\hline Property & Values \\
\hline$E_{1}$ & $133.86 \mathrm{GPa}$ \\
$E_{2}=E_{3}$ & $7.706 \mathrm{GPa}$ \\
$G_{12}=G_{13}$ & $4.306 \mathrm{GPa}$ \\
$G_{23}$ & $2.76 \mathrm{GPa}$ \\
$v_{12}=v_{13}$ & 0.301 \\
$v_{23}$ & 0.396 \\
$V_{\mathrm{f}}$ & 0.55 \\
$F_{1 \mathrm{~T}}$ & $1500 \mathrm{MPa}$ \\
$F_{1 \mathrm{C}}$ & $1200 \mathrm{MPa}$ \\
$F_{2 \mathrm{~T}}$ & $40 \mathrm{MPa}$ \\
$F_{2 \mathrm{C}}$ & $246 \mathrm{MPa}$ \\
$F_{6}$ & $68 \mathrm{MPa}$ \\
\hline
\end{tabular}

Table 1. Material properties of the (AS4D/9310) carbon/epoxy composite.

of each configuration is evaluated using the commercial finite element analysis software ABAQUS. In the second module, the neural network (ANN) structure is constructed using MATLAB code and it is trained using the sample data generated in the first module. The genetic algorithm, in which the trained ANN is used to predict the fitness values, is used as the optimization tool in the third module.

2.3. Finite element analysis and data generation. The finite element method is used to analyze the structure when the geometry, material property or loading condition is irregular. The commercial finite element analysis software ABAQUS is used in this paper to equip the sample data so as to train and test the ANN. The stacking sequences of the rectangular composite plate made with the elliptical cut-out are randomly generated from the specified design space and the buckling strength and the ply stresses (through which the safety factor is found using Tsai-Wu criterion) of each configuration are calculated using ABAQUS. The MATLAB code is used to generate the stacking sequences randomly and python script is used to interface ABAQUS with MATLAB. The material properties listed in Table 1 are applied to the plate. The maximum number of plies is set as 24 , whereas each ply has a uniform thickness of 0 or $0.125 \mathrm{~mm}$. The value of ply thickness is set as 0 so as to vary the number of plies.

The simply supported boundary conditions (as given in Equation (2)) and biaxial compressive load are applied along the edges of the plate as shown in Figure 2. The finite element model of the plate is generated using four node shell element (S4R) where each node has six degrees of freedom. The sample finite element model of the plate with cut-out is shown in Figure 3. In this paper, the number of elements is optimally found as 5300 by using the convergence graph shown in Figure 4.

$$
\begin{aligned}
& w_{0}(x, 0)=0, \quad w_{0}(x, b)=0, \quad w_{0}(0, y)=0, \quad w_{0}(a, y)=0, \\
& M_{x x}(0, y)=0, \quad M_{x x}(a, y)=0, \quad M_{y y}(x, o)=0, \quad M_{y y}(x, b)=0 .
\end{aligned}
$$

2.4. Artificial neural network. As the design space of this work is critically increased and FEA is required to analyze the plate, ANN is used in this paper to predict the buckling strength and the safety 


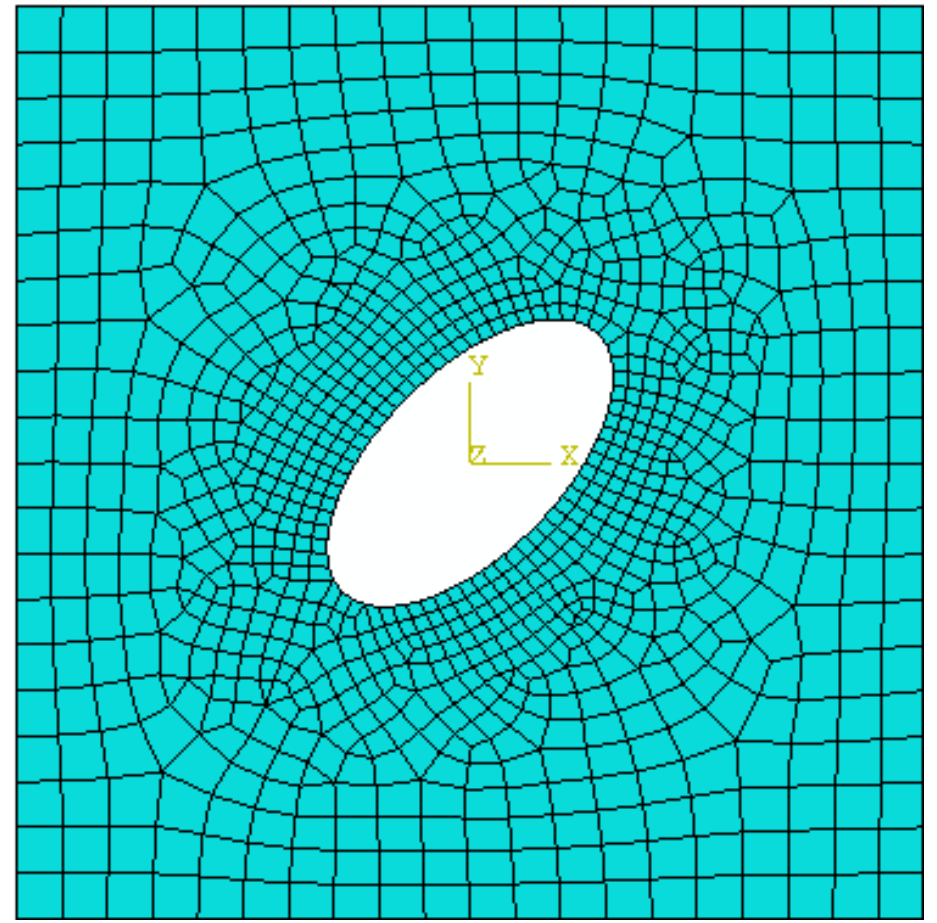

Figure 3. Finite element model of the composite plate with cut-out.

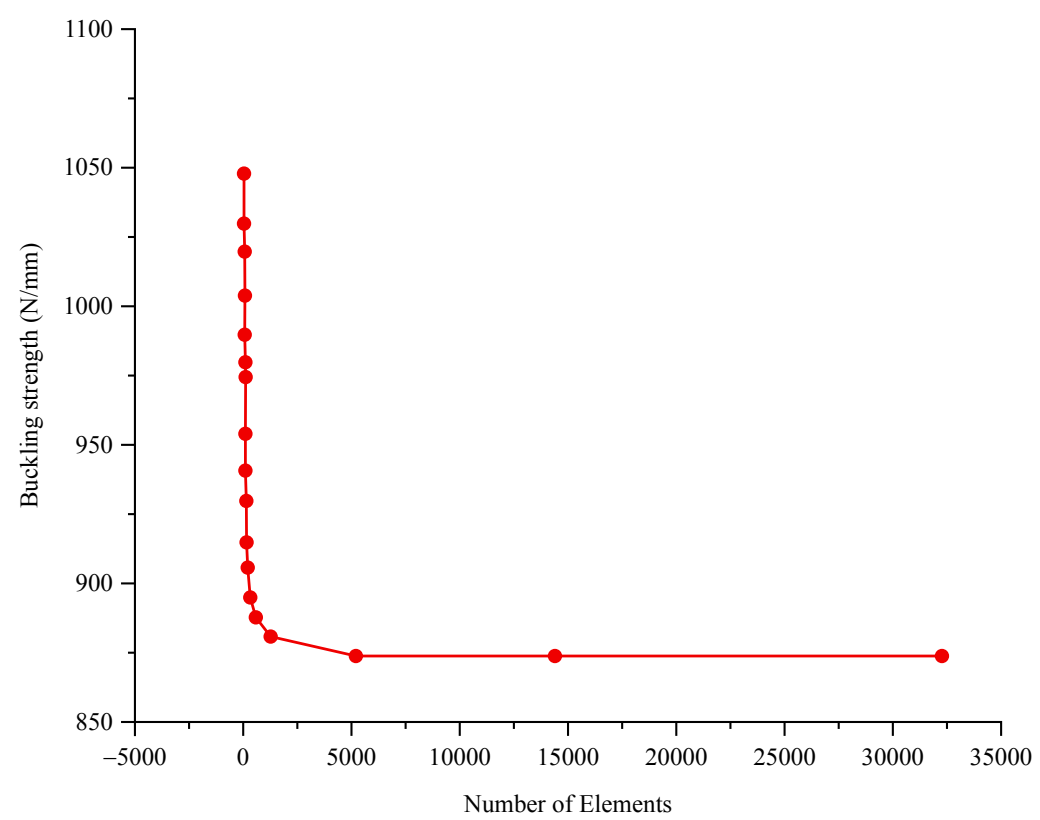

Figure 4. Convergence of number of elements. 


\begin{tabular}{|c|l|c|}
\hline Sl.No & Training Algorithm & Acronym \\
\hline 1 & resilient backpropagation & RP \\
2 & scaled conjugate gradient & SCG \\
3 & conjugate gradient with Powell/Beale restarts & CGB \\
4 & Fletcher-Powell conjugate gradient & CGF \\
5 & Polak-Ribière conjugate gradient & CGP \\
6 & Levenberg-Marquardt & LM \\
7 & BFGS quasi-Newton & BFG \\
\hline
\end{tabular}

Table 2. Various training algorithms.

factor during the optimization process. A multilayer feed-forward back- propagation neural network is used. The neural network is built in four stages. In the first stage, the sample data with their targets are collected. The network object with suitable neuron in each layer, number of layers, transfer function for each layer and the training algorithm of the network are chosen in the second stage. The created network is trained in stage three with the samples generated in stage one. The network is tested in stage four with the remaining samples and after the satisfaction of the performance of the network with these test samples, the network is simulated for the new inputs.

The performance of the neural network during the training and after the training periods highly depends on the choice of the network objects such as the numbers of hidden layers, number of neurons, transfer functions and the training algorithm. Yuen and Lam [2006] mentioned that these parameters are to be decided based on the experience or rule of thumb only. Bolanča et al. [2014] obtained the network structure by optimally varying these parameters. Kermanshahi and Iwamiya [2002] and Chakraborty [2005] also recommended for finding the network objects using the trial and error method. Four layers network is chosen for this work with the neurons 24, 30, 15 and 2, respectively. The input and output layers consist of 24 and 2 neurons, respectively, as the ANN has 24 inputs (layer angles) and 2 outputs (buckling strength and safety factor). The number of neurons in the hidden layers, transfer functions and the training algorithm are chosen based on the trial and error method [Mishra et al. 2010]. Since the design space is increased here with the choice of dispersed layer angles, 1000 samples of stacking sequences with their targets are generated for each ply angle interval. The inputs and the targets are normalized between -1 to 1 . Tan-sigmoid transfer function is used for the first three layers and linear transfer function is used in the last layer. Seven networks having same number of layers, neurons and same type of transfer functions have been constructed and they have been trained separately using the various training algorithms given in the Table 2 .

After the successful training, the networks were validated using the new data. Further, the average and the maximum error have also been found for each training algorithm and they are compared in Figure 5. It shows that the error level is high for the network trained by BFG type training algorithm and less for the network trained by CGF type training algorithm. Similarly, the average error rate is found to be maximum for the network trained by BFG type training algorithm and minimum for the network trained by CGF type training algorithm. Hence, the CGF type training algorithm is selected to train the network. The architecture of ANN is shown in Table 3. 

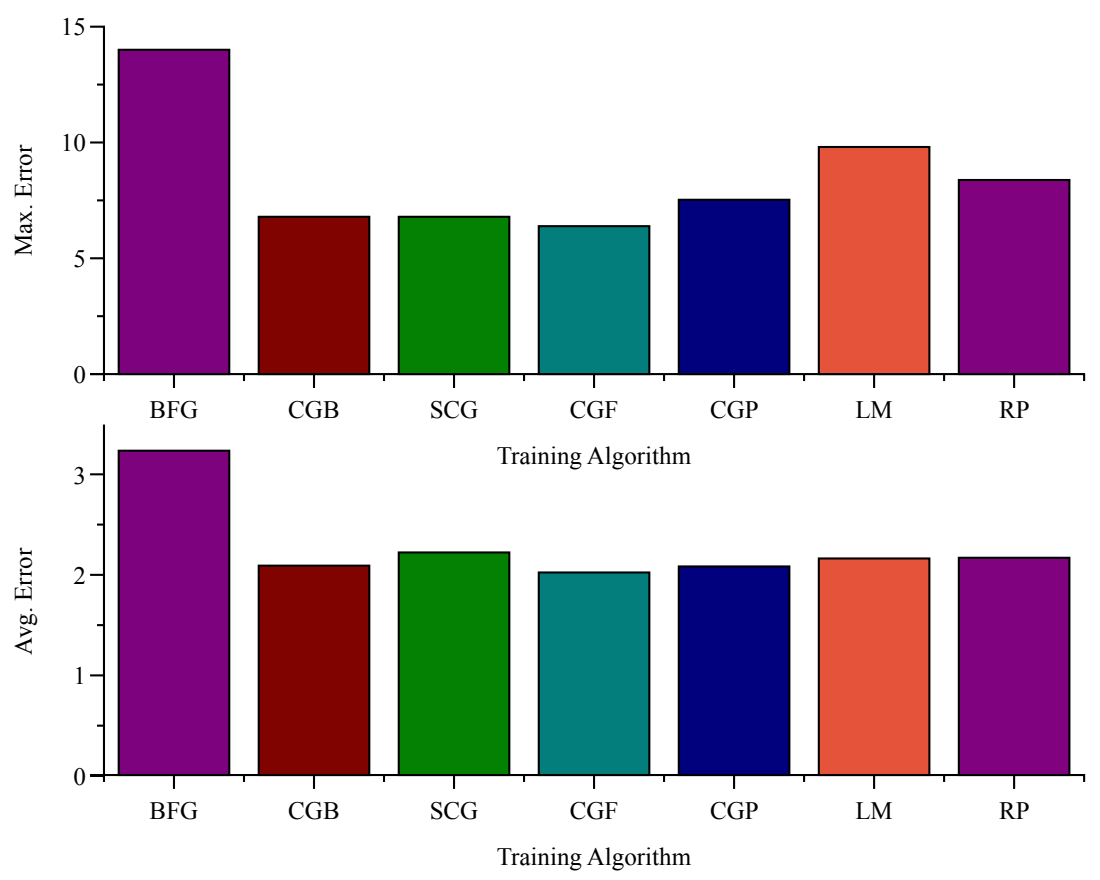

Figure 5. Networks error comparisons.

\begin{tabular}{|c|c|c|c|}
\hline Ply angle interval & Neurons in each layer & Transfer functions & Training algorithm \\
\hline $45^{\circ}$ & $24-30-15-2$ & Tansig-Tansig-Tansig-Linear & FRCGA $^{\dagger}$ \\
$30^{\circ}$ & $24-30-15-2$ & Tansig-Tansig-Tansig-Linear & FRCGA $^{\dagger}$ \\
$15^{\circ}$ & $24-30-15-2$ & Tansig-Tansig-Tansig-Linear & FRCGA $^{\dagger}$ \\
$5^{\circ}$ & $24-30-15-2$ & Tansig-Tansig-Tansig-Linear & FRCGA $^{\dagger}$ \\
\hline
\end{tabular}

Table 3. Architecture of ANN. ${ }^{\dagger}$ Fletcher-Reeves conjugate gradient algorithm.

2.5. Nondominated sorting genetic algorithm. The nondominated sorting genetic algorithm (NSGAII), proposed by Deb [2001], is used in this research work to obtain the Pareto optimal designs of the multiobjective optimization problem. It comes under the category of elitist multiobjective evolutionary algorithm. As the name suggests, an elite-preserving operator favors the elites of a population by giving them an opportunity to be directly carried over to the next generation. In this way, a good solution found at the beginning of the run will never be removed unless a better solution is found out.

Initially, the population is randomly generated and the solutions are sorted into each front based on nondomination. The dual objectives in the multiobjective optimization problem are maintained by using a fitness assignment scheme that prefers nondominated solutions. In the current population, the very first front is absolutely a nondominant set and the second front is dominated only by the solutions available in the first front and the sorting of fronts happen so on. A solution "S1" is said to dominate another solution "S2", if the following conditions are completely satisfied: 
- The solution $\mathrm{S} 1$ is not inferior to $\mathrm{S} 2$ in all the objectives.

- The solution S1 is strictly better than S2 in at least one objective.

A rank (fitness) value is assigned to the individuals of each front based on the front number in which they exist. Solutions available in the first front are assigned with a fitness value of 1 and solutions of the second front are assigned with a fitness value of 2 and so on. In addition to the fitness value, a factor called crowding distance is also calculated for each solution. The main objective of finding the crowding distance is to show the closeness of a solution to the ones of its neighbours. The systematic procedure of finding the crowding distance is given below.

- Let "P" be the number of solutions existing in a front and " $\mathrm{M}$ " the number of design objectives.

- For each objective function, the solutions in the front are sorted in the worst order of its objective values (fm) and the sorted indices vector ( Im) is found (usually the size of "I" is equal to the size of "P").

- A large distance values are assigned to the boundary solutions as given in (3).

$$
d_{1}^{m}=d_{p}^{m}=\infty
$$

- For the remaining solutions $(j=2$ to $P-1)$, the crowding distance is calculated using (4).

$$
d_{j}^{m}=I_{j}^{m}+\frac{I_{j+1}^{m}-I_{j-1}^{m}}{f_{\max }^{m}-f_{\min }^{m}} .
$$

The parents are selected from the current population based on their rank and crowding distance by using the tournament selection. The solution having a lower rank than another solution is selected. If both solutions are having the same rank, then the crowding distance is used to select the best solution. The solution with higher crowding distance is selected to the mating pool to reproduce the offspring. The uniform crossover and mutation operators are applied to generate the next populations. As the number of plies is also included as one of the design variables, the size of the chromosome in the multiobjective optimization is increased twice than that of the size used in the single objective optimization. The processes of uniform crossover and mutation applied in the multiobjective optimization problem are given in Tables 4 and 5 .

The symmetric laminated composite plate having maximum of eight plies above or below to the mid-plane is considered in this example. As number of plies, angle of each ply and stacking sequence are optimized in the multiobjective optimization problem, each chromosome has sixteen genes in this example. The genes in first half of the chromosome represent the ply angle, whereas the genes in the next half of the chromosome represent the ply thickness. The genes in the second half of the chromosome remain unchanged during the crossover and mutation processes, as each ply has a constant thickness of $0.1 \mathrm{~mm}$.

A distinct operator, named as ply deletion operator, is additionally used in the multiobjective optimization to vary the number of plies of the laminated composite plate. The ply deletion operator is used to take out a gene from the second half of the chromosome and to replace it with an empty stack code. This operator is applied based on the probability given by the user. If the randomly generated number is greater than the user given probability, the thickness of any ply is randomly chosen and set as zero. An example for the ply deletion operator is given in Table 5. 


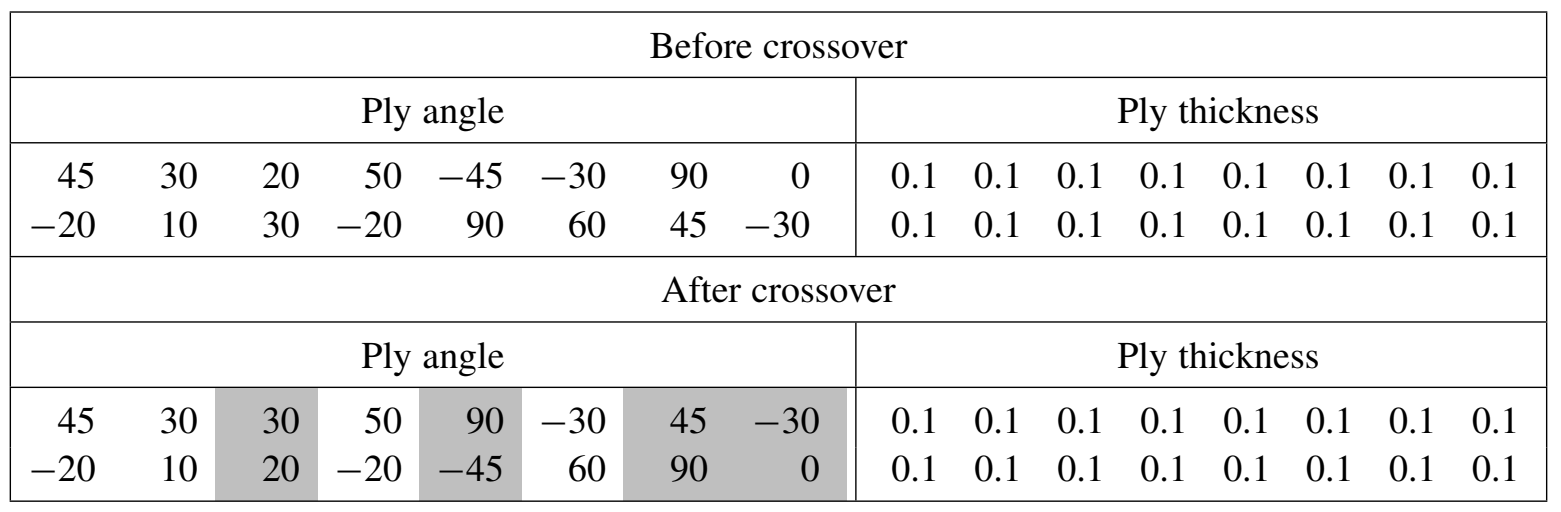

Table 4. An example of uniform crossover for NSGA-II.

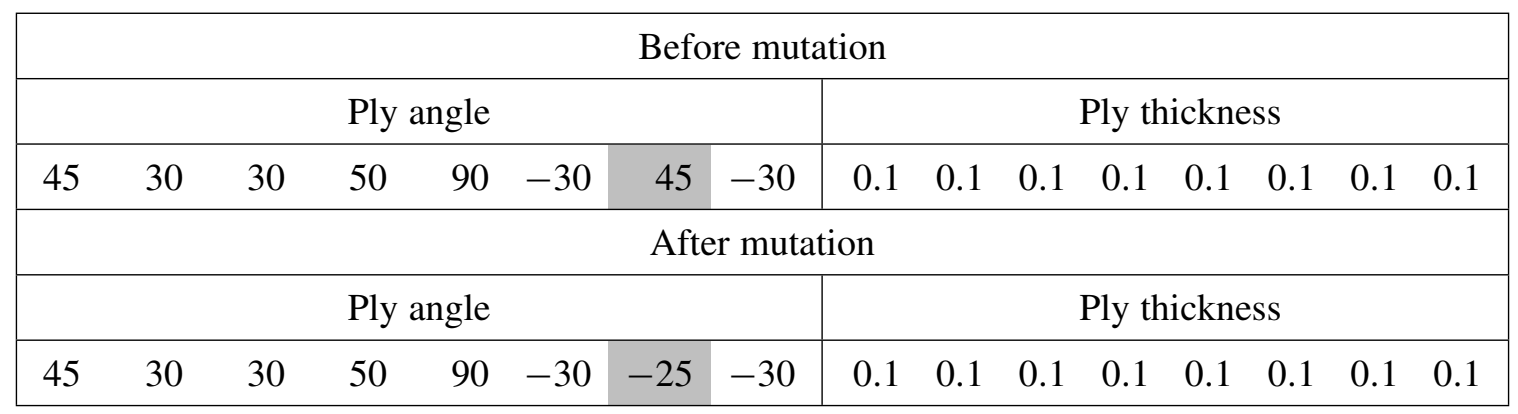

Table 5. An example of uniform mutation for NSGA-II.

\begin{tabular}{|c|c|c|c|c|c|c|c|c|c|c|c|c|c|c|c|}
\hline \multicolumn{16}{|c|}{ Before ply deletion } \\
\hline \multicolumn{8}{|c|}{ Ply angle } & \multicolumn{8}{|c|}{ Ply thickness } \\
\hline 45 & 30 & 30 & 50 & 90 & -30 & 45 & -30 & 0.1 & 0.1 & 0.1 & 0.1 & 0.1 & 0.1 & 0.1 & 0.1 \\
\hline \multicolumn{16}{|c|}{ After ply deletion } \\
\hline \multicolumn{8}{|c|}{ Ply angle } & \multicolumn{8}{|c|}{ Ply thickness } \\
\hline 45 & 30 & 30 & 50 & 90 & -30 & 45 & -30 & 0.1 & 0.1 & 0.1 & 0.1 & 0.1 & 0.1 & 0 & 0.1 \\
\hline
\end{tabular}

Table 6. An example of ply deletion operator for NSGA-II.

\section{Numerical results and discussion}

3.1. Validation of neural network. In general, the trained network performs well during the training session. However, there may be possibilities of over fitting when the same network is applied to the newly generated data. Hence, the trained network must be validated before it is included in the optimization procedure. The laminated composite plate made with the elliptical cut-out is considered, in which the 

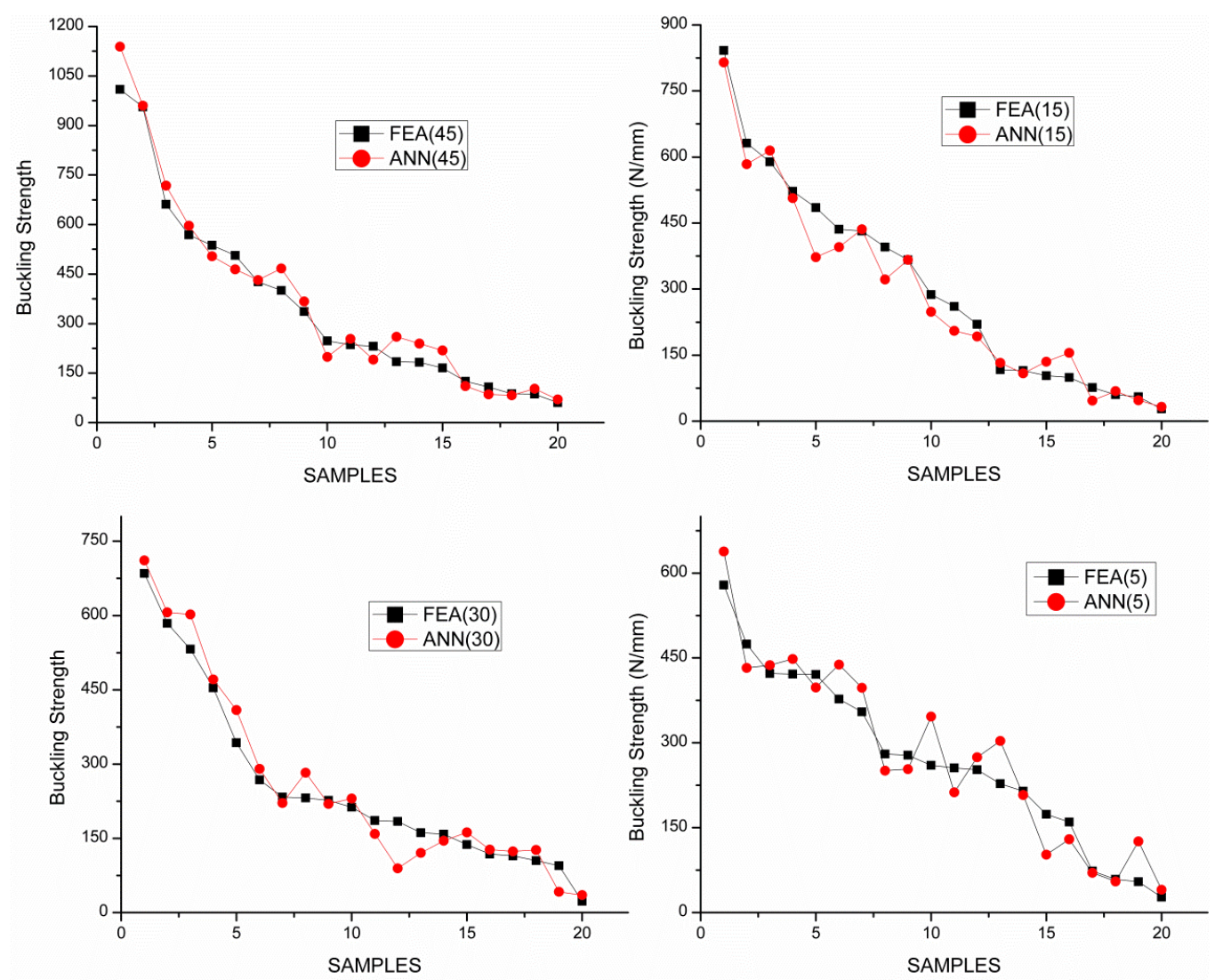

Figure 6. NN predictions versus actual targets for various ply angle intervals.

cutout is oriented at an angle $60^{\circ}$ and located at the center of the plate as shown in Figure 1. Twenty stacking sequences are generated for different ply angle intervals and the buckling strengths have been predicted using the trained networks as well as the finite element method. The results obtained using FEM and ANN have been compared in the Figure 6, which shows that the predictions of outputs are nearer to the actual targets in all the cases.

3.2. Multiobjective optimization. The ANN based NSGA-II is constructed and used to find the Pareto optimal solutions of the complex multiobjective optimization of the laminated composite plate with cutout. The maximum thickness of the plate is set as $3 \mathrm{~mm}$ whereas each ply has a thickness of $0.125 \mathrm{~mm}$. The number of plies, angle of each ply and stacking sequences are optimized for five different ply angle intervals $\left(45^{\circ}, 30^{\circ}, 15^{\circ}\right.$ and $\left.5^{\circ}\right)$. Hence, five different networks are constructed, trained and used for the multiobjective optimization problem. After the training, the networks are validated using new data. The performances of the networks during the testing period are shown in Figure 7 and it shows that the predictions of the networks are very close to the FEM results. Hence, the networks are recommended to be used in NSGA-II to predict the fitness values.

The Pareto optimal solutions obtained for different ply angle intervals using ANN based NSGA-II are shown in Figure 8. The results prove that the number of solutions in the Pareto optimal set is significantly 

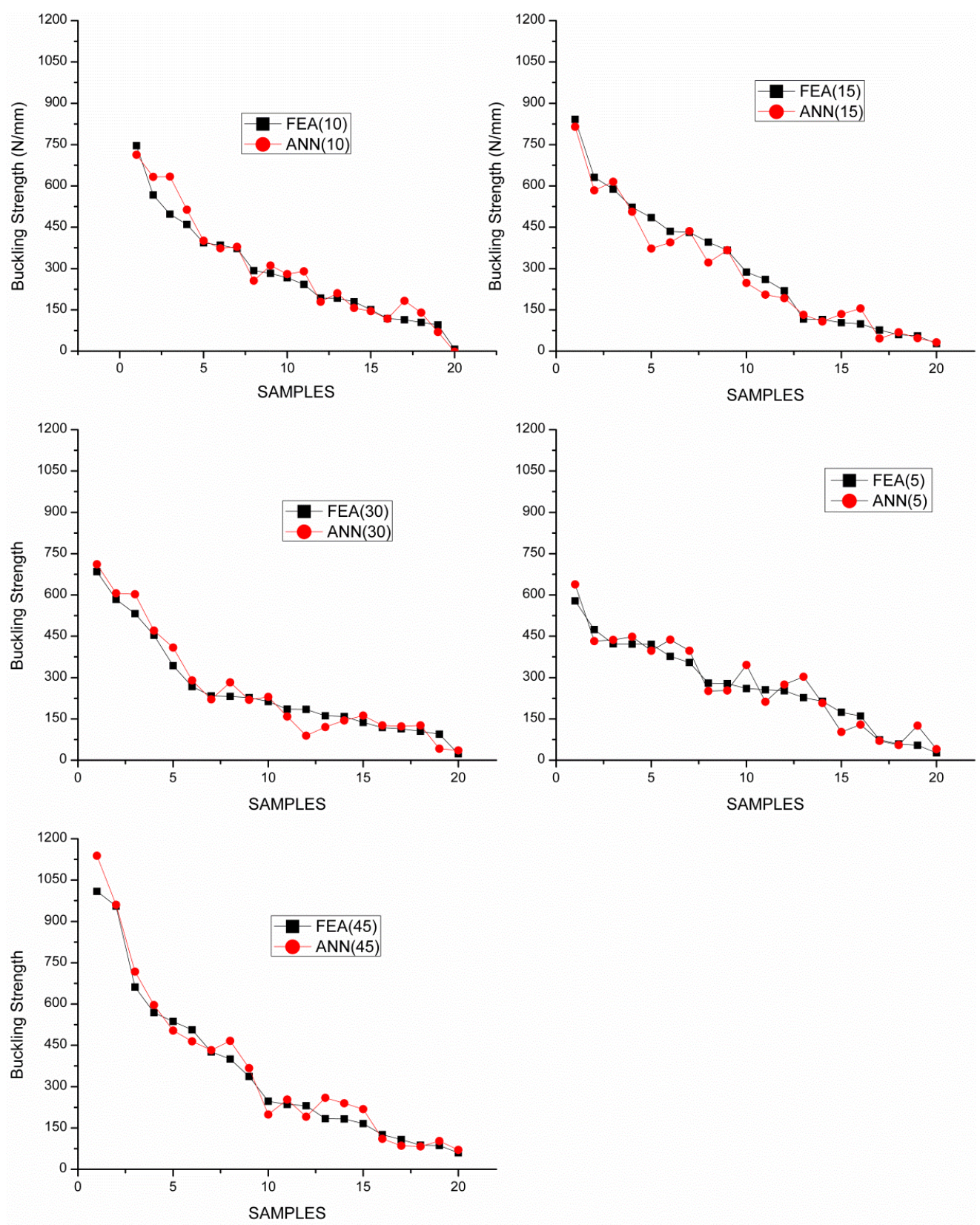

Figure 7. Performance of the networks during the testing.

increased by reducing the ply-angle interval. Only three solutions were found in the Pareto optimal set when conventional ply angles have been optimized. The number of solutions in the Pareto optimal set was increased from three to five when the ply angle interval has been reduced from $45^{\circ}$ to $30^{\circ}$. Further, it is found that the number of solutions was increased to six and twelve when the ply angle interval has 


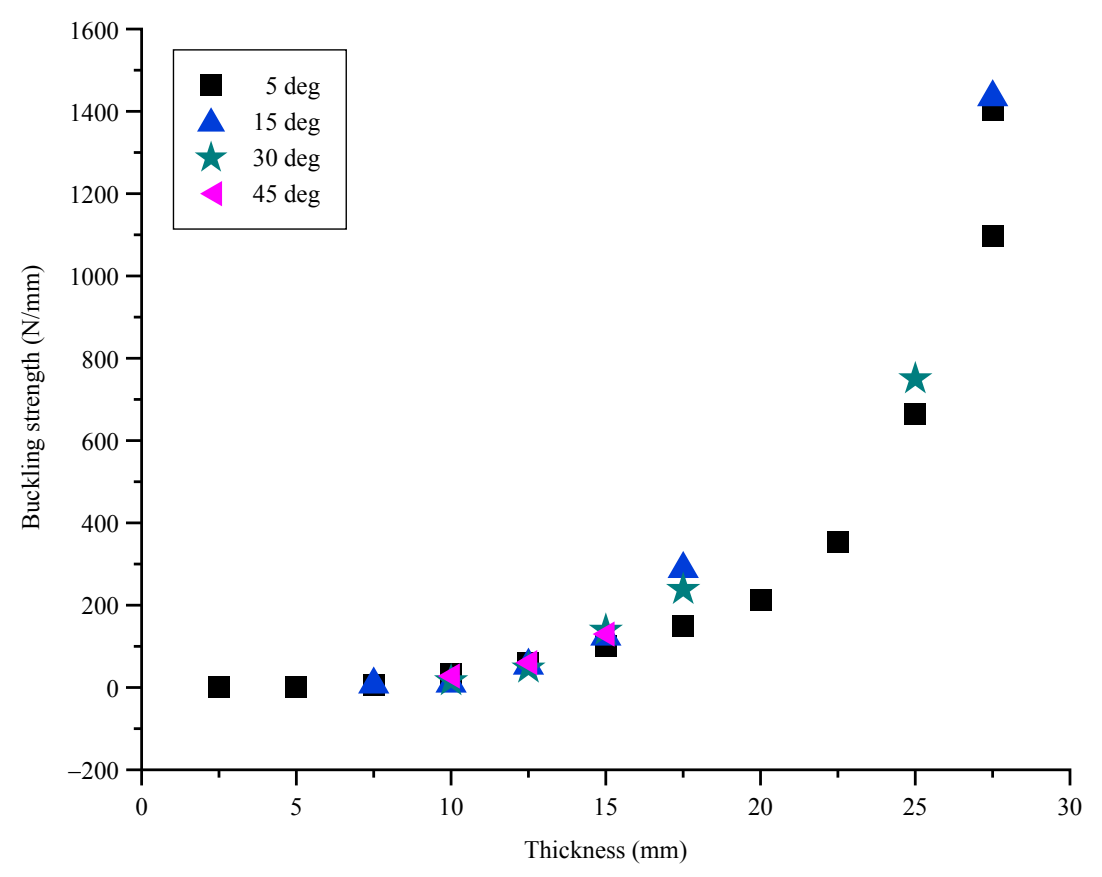

Figure 8. Pareto optimal solutions for the composite plate with cut-out.

been reduced to $15^{\circ}$ and $5^{\circ}$, respectively. The results also show that the boundaries of the Pareto optimal front are significantly increased by using the concept of ply angles having the reduced intervals.

Based on the trial and error method the maximum number of generations is set as 300 , whereas each generation works with 40 populations. If FEM had been used to analyze the plate, ABAQUS would have been called 12,000 times during the optimization process. As each run of FEM consumes approximately 18 seconds, more than sixty hours are required to complete the stacking sequence optimization problem. Further, GA is one of the stochastic optimization (SO) methods and hence, it has to be run several times in order to ensure for the global optima. This makes the FEM based optimization process more complex. However, the same optimization problem has been completed in less than 15 minutes using ANN based optimization method. Though the data generation task (for which FEM must be used) consumes about 5 hours, the weights and biases of the trained network are stored and used in future at any number of times in order to find the optimum GA control parameters and to ensure for global optima.

The number of Pareto optimal solutions obtained for various ply angle intervals are given in Table 7 and they are compared based on the objective values of the boundary solutions. It is found that only three Pareto optimal solutions were obtained when conventional ply angles have been optimized. The number of Pareto optimal solutions was increased from three to five by reducing the ply angle interval from $45^{\circ}$ to $30^{\circ}$. Further, the number of solutions in the Pareto optimal set was increased to six and twelve, when the ply angle interval has been reduced to $15^{\circ}$ and $5^{\circ}$, respectively. Thus, the concept of ply angles having the reduced intervals not only reduces the number of groupings of plies having the same orientation, but also increases the number of solutions in the Pareto optimal set as well as enhances 


\begin{tabular}{|c|c|c|c|c|c|c|c|}
\hline \multirow[t]{3}{*}{$\begin{array}{c}\text { Ply angle } \\
\text { interval (" } \Delta ")\end{array}$} & \multirow[t]{3}{*}{$\begin{array}{l}\text { Number of } \\
\text { solutions } \\
\text { in the Pareto } \\
\text { optimal set }\end{array}$} & \multicolumn{3}{|c|}{$\begin{array}{l}\text { Maximum buckling strength } \\
\text { and the corresponding } \\
\text { plate thickness }\end{array}$} & \multicolumn{3}{|c|}{$\begin{array}{l}\text { Maximum plate thickness } \\
\text { and the corresponding } \\
\text { buckling strength }\end{array}$} \\
\hline & & \multicolumn{2}{|c|}{ Buckling strength $^{\dagger}$} & \multirow[t]{2}{*}{ Thickness ${ }^{\dagger \dagger}$} & \multirow[t]{2}{*}{ Thickness $^{\dagger \dagger}$} & \multicolumn{2}{|c|}{ Buckling strength $^{\dagger}$} \\
\hline & & ANN & FEA & & & ANN & FEA \\
\hline $45^{\circ}$ & 3 & 28.29 & 27.88 & 10 & 15 & 130.55 & 134.7 \\
\hline $30^{\circ}$ & 5 & 16.36 & 16.14 & 10 & 25 & 750.23 & 738.45 \\
\hline $15^{\circ}$ & 6 & 6.856 & 7.05 & 7.5 & 27.5 & 1433.25 & 1485.2 \\
\hline $5^{\circ}$ & 12 & 1.2 & 1.17 & 2.5 & 27.5 & 1403.15 & 1359.52 \\
\hline
\end{tabular}

Table 7. Comparison of Pareto optimal solutions. Units are ${ }^{\dagger} \mathrm{N} / \mathrm{mm}$ and ${ }^{\dagger \dagger} \mathrm{mm}$.

the degree of the objective functions. In addition, the predictions of ANN are once again compared using FEA in Table 7, which proves that the performance of ANN is quite good even for the new data.

\section{Conclusions}

The Pareto optimal solutions for the laminated composite plate made with cut-out have been obtained using ANN based NSGA-II. The predictions of ANN have been found to be very close to the actual solutions. As weights and biases of the network can be stored, it is able to run NSGA several times to ensure the global optima. The number of solutions in the Pareto optimal set has been significantly increased by reducing the ply angle interval. The boundaries of the Pareto optimal set have been increased using the concept of reduced ply angle intervals. Accordingly, the degree of the objective functions has been enriched.

\section{References}

[Al-Assaf and El Kadi 2001] Y. Al-Assaf and H. El Kadi, "Fatigue life prediction of unidirectional glass fiber/epoxy composite laminae using neural networks", Compos. Struct. 53:1 (2001), 65-71.

[Al-Haik et al. 2006] M. S. Al-Haik, M. Y. Hussaini, and H. Garmestani, "Prediction of nonlinear viscoelastic behavior of polymeric composites using an artificial neural network”, Int. J. Plast. 22:7 (2006), 1367-1392.

[Al Qablan et al. 2009] H. Al Qablan, H. Katkhuda, and H. Dwairi, "Assessment of buckling behavior of square composite plates with circular cutout subjected to in-plane shear", Jordan J. Civ. Eng. 3:2 (2009), 184-195.

[Almeida and Awruch 2009] F. S. Almeida and A. M. Awruch, "Design optimization of composite laminated structures using genetic algorithms and finite element analysis", Compos. Struct. 88:3 (2009), 443-454.

[Aydin Komur et al. 2010] M. Aydin Komur, F. Sen, A. Atas, and N. Arslan, "Buckling analysis of laminated composite plates with an elliptical/circular cutout using FEM", Adv. Eng. Softw. 41:2 (2010), 161-164.

[Aymerich and Serra 2008] F. Aymerich and M. Serra, "Optimization of laminate stacking sequence for maximum buckling load using the ant colony optimization (ACO) metaheuristic", Compos. A Appl. Sci. Manuf. 39:2 (2008), 262-272.

[Bilgehan 2011] M. Bilgehan, "Comparison of ANFIS and NN models: with a study in critical buckling load estimation", Appl. Soft Comput. J. 11:4 (2011), 3779-3791.

[Bolanča et al. 2014] T. Bolanča, v. Ukić, I. Peternel, H. Kušić, and Božić, "Artificial neural network models for advanced oxidation of organics in water matrix-comparison of applied methodologies", Indian J. Chem. Tech. 21:1 (2014), 21-29. 
[Campbell 2010] F. C. Campbell, Structural composite materials, ASM International, Materials Park, OH, 2010.

[Cardozo et al. 2011] S. D. Cardozo, H. Gomes, and A. M. Awruch, "Optimization of laminated composite plates and shells using genetic algorithms, neural networks and finite elements”, Lat. Amer. J. Solids Struct. 8:4 (2011), 413-427.

[Chakraborty 2005] D. Chakraborty, "Artificial neural network based delamination prediction in laminated composites", Mater. Des. 26:1 (2005), 1-7.

[Deb 2001] K. Deb, Multi-objective optimization using evolutionary algorithms, Wiley, Chichester, 2001.

[Emmanuel Nicholas et al. 2014] P. Emmanuel Nicholas, K. P. Padmanaban, and D. Vasudevan, "Buckling optimization of laminated composite plate with elliptical cutout using ANN and GA", Struct. Eng. Mech. 52:4 (2014), 815-827.

[Erklig and Yeter 2012] A. Erklig and E. Yeter, "The effects of cutouts on buckling behavior of composite plates", Sci. Eng. Compos. Mater. 19:3 (2012), 323-330.

[Iyengar and Vyas 2011] N. G. R. Iyengar and N. Vyas, "Optimum design of laminated composite under axial compressive load”, Sadhana Acad. Proc. Eng. Sci. 36:1 (2011), 73-85.

[Karnik et al. 2008] S. R. Karnik, V. N. Gaitonde, J. C. Rubio, A. E. Correia, A. M. Abrão, and J. P. Davim, "Delamination analysis in high speed drilling of carbon fiber reinforced plastics (CFRP) using artificial neural network model", Mater. Des. 29:9 (2008), 1768-1776.

[Kermanshahi and Iwamiya 2002] B. Kermanshahi and H. Iwamiya, "Up to year 2020 load forecasting using neural nets", Int. J. of Elec. Power Energy Sys. 24:9 (2002), 789 - 797.

[Kim 2007] J.-S. Kim, "Development of a user-friendly expert system for composite laminate design", Compos. Struct. 79:1 (2007), 76-83.

[Kim et al. 2005] J.-S. Kim, N.-P. Kim, and S.-H. Han, "Optimal stiffness design of composite laminates for a train carbody by an expert system and enumeration method", Compos. Struct. 68:2 (2005), 147-156.

[Liu et al. 2006] Y. Liu, F. Jin, and Q. Li, "A strength-based multiple cutout optimization in composite plates using fixed grid finite element method", Compos. Struct. 73:4 (2006), 403-412.

[Lopes et al. 2010] C. S. Lopes, Z. Gürdal, and P. P. Camanho, "Tailoring for strength of composite steered-fibre panels with cutouts", Compos. A Appl. Sci. Manuf. 41:12 (2010), 1760-1767.

[Mishra et al. 2010] R. Mishra, J. Malik, I. Singh, and J. a. P. Davim, "Neural network approach for estimating the residual tensile strength after drilling in uni-directional glass fiber reinforced plastic laminates", Mater. Des. 31:6 (2010), 2790-2795.

[Omkar et al. 2009] S. N. Omkar, R. Khandelwal, T. V. S. Ananth, G. Narayana Naik, and S. Gopalakrishnan, "Quantum behaved particle swarm optimization (QPSO) for multi-objective design optimization of composite structures", Expert Syst. Appl. 36:8 (2009), 11312-11322.

[Omkar et al. 2011] S. N. Omkar, J. Senthilnath, R. Khandelwal, G. Narayana Naik, and S. Gopalakrishnan, "Artificial bee colony (ABC) for multi-objective design optimization of composite structures", Appl. Soft Comput. J. 11:1 (2011), 489-499.

[Reddy et al. 2013] B. S. Reddy, J. S. Kumar, and K. V. K. Reddy, "Prediction of deflection and stresses of laminated composite plate with an artificial neural network aid", Int. J. Appl. Sci. Eng. 11:4 (2013), 393-413.

[Rocha et al. 2014] I. B. C. M. Rocha, E. Parente, Jr., and A. M. C. Melo, "A hybrid shared/distributed memory parallel genetic algorithm for optimization of laminate composites", Compos. Struct. 107:1 (2014), 288-297.

[Tsao and Hocheng 2008] C. C. Tsao and H. Hocheng, "Evaluation of thrust force and surface roughness in drilling composite material using Taguchi analysis and neural network", J. Mater. Process. Technol. 203:1-3 (2008), 342-348.

[Yuen and Lam 2006] K.-V. Yuen and H.-F. Lam, "On the complexity of artificial neural networks for smart structures monitoring", Eng. Struct. 28:7 (2006), 977 - 984.

[Zheng et al. 2009] S.-J. Zheng, Z.-Q. Li, and H.-T. Wang, "Research on delamination monitoring for composite structures based on HHGA-WNN", Appl. Soft Comput. J. 9:3 (2009), 918-923.

Received 26 May 2015. Revised 30 Sep 2015. Accepted 5 Oct 2015.

P. EMMANUEL NichOlas: p.emmanuelnicholas@gmail.com

Mechanical Engineering, PSNA College of Engineering and Technology, Dindigul 624622, India 
M. C. LENIN BABU: mcbhabu@gmail.com

School of Mechanical \& Building Sciences, VIT University, Chennai 600127, India

A. SATHYA Sofia: sathyasofia@gmail.com

Computer Science Engineering, PSNA College of Engineering and Technology, Dindigul 624622, India 


\title{
JOURNAL OF MECHANICS OF MATERIALS AND STRUCTURES
}

\author{
msp.org/jomms
}

Founded by Charles R. Steele and Marie-Louise Steele

\section{EDITORIAL BOARD}

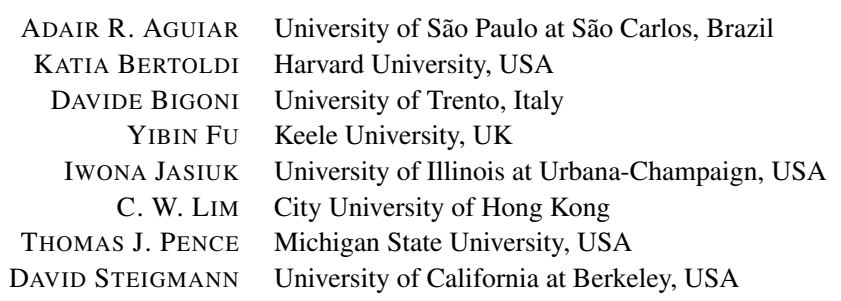

\section{ADVISORY BOARD}

J. P. CARTER University of Sydney, Australia

D. H. Hodges Georgia Institute of Technology, USA

J. HUTCHINSON Harvard University, USA

D. PAMPlona Universidade Católica do Rio de Janeiro, Brazil

M. B. RUBin Technion, Haifa, Israel

PRODUCTION production@msp.org

SILvio Levy Scientific Editor

See msp.org/jomms for submission guidelines.

JoMMS (ISSN 1559-3959) at Mathematical Sciences Publishers, 798 Evans Hall \#6840, c/o University of California, Berkeley, CA 94720-3840, is published in 10 issues a year. The subscription price for 2016 is US \$575/year for the electronic version, and $\$ 735 /$ year ( $\$ 60$, if shipping outside the US) for print and electronic. Subscriptions, requests for back issues, and changes of address should be sent to MSP.

JoMMS peer-review and production is managed by EditFLOW ${ }^{\circledR}$ from Mathematical Sciences Publishers.

PUBLISHED BY

mathematical sciences publishers

nonprofit scientific publishing

http://msp.org/

(C) 2016 Mathematical Sciences Publishers 


\title{
Journal of Mechanics of Materials and Structures
}

\author{
Volume 11, No. $2 \quad$ March 2016
}

The effect of small scale on the free vibration of functionally graded truncated conical shells

Yaghoub TAdi Beni and Fahimeh Mehralian

Conditions for the localisation of plastic deformation in temperature sensitive viscoplastic materials MARTIN K. PAESOLd, ANDREW P. BASSOM, KLAUS RegenaUeR-Lieb and Manolis VeVEAKIS

A simple hard-particle collision model with a smooth transition to full slip

Multiobjective optimization of laminated composite plate with elliptical cut-out using ANN based NSGA-II

P. Emmanuel Nicholas, M. C. Lenin Babu and A. Sathya Sofia

Analytical estimates for the lateral thrust in bolted steel buckling-restrained braces Guido Bregoli, Francesco Genna and Giovanni Metelli 